\title{
Review
}

\section{Our bodies, whose property?}

\author{
Anne Phillips \\ Princeton University Press, Princeton and Oxford, 2013, vii+202 pp., \\ ISBN: 978-0691150864
}

Contemporary Political Theory (2016) 15, e8-e10. doi:10.1057/cpt.2015.27; published online 9 June 2015

In this thought-provoking book, Anne Phillips poses the question, 'What - if anything makes the body special?' (p. 1). She goes on to consider the implications and consequences of thinking of the body as something that we own in the contexts of rape, commercial surrogacy, organ donation and medical trials. Phillips says she was inspired by feminist politics and literature and their focus on embodied politics to query the mind/body dualism of the case for markets in bodies, and to ask what justifies restrictions on free individuals choosing to trade in their bodies and body parts. Her answers are refreshing, rewarding, thoughtful and fair, sometimes challenging and occasionally frustrating. After several readings, I still find the book's framework difficult and its starting point in property models of rape disconnected from its other themes. Phillips' discussion of the harm of rape, and the ways in which bodily experience is sidestepped, expunged or poorly understood (p. 53) is interesting and convincing, and she is surely right to argue that rape is often presented in ways that minimise the significance of pain and fear, creating 'distancing and fragmentation [that] is characteristic of property language, even when this is not explicitly applied' (p. 64). The difficulty is how to integrate these arguments with the book's wider discussion of the sale and purchase of intimate bodily services. The book's conclusion that we need to consider very carefully 'the risks associated with regarding our bodies as property and the threat to principles of human equality when we routinely send bodies to market' (p. 155) does not quite succeed in bringing the different strands together.

The book's key argument is for equality based on the recognition of our shared vulnerability and common experience of living as embodied beings in the same world. Phillips argues that our ability to think of others as our equals is bound up with our capacity to see those others as like us, and having bodies is 'one crucial way in which we are all alike' (p. 11). That shared vulnerability and common experience is all too often undercut and undermined by inequality, and the book focuses on the point at which 'some people's bodies become the means to patch up the bodies of others' (p. 11) as deeply threatening to equality. The market in organs, in particular, 
'seems almost designed to ensure a division of the world into two kinds of being, with the fact of payment relieving the purchasers of any obligation to think themselves into the sellers' shoes' (p. 117). The exchange relies on systematic inequality between recipients and vendors. Some of us are positioned as buyers and others as sellers just because of our inequality, and that difference between us cannot be fudged as anything to do with differing tastes or talents or skills.

Most of this book is about the complicated and sometimes fraught relationship between bodies, property and markets. In Phillips' view 'bodies alert us to reciprocity and what we have in common; property alerts us to inequality and what keeps us apart; the choice of language has significant implications' (p. 45). In the process of drawing out this tension, the book makes some cogent points about the tricky politics of agency and coercion and, in particular, the problem of fetishizing choice and private property in ways that paradoxically end up denying individual agency. The 'pervasive individualism' in the claim to a property right and its deadening effect on equality is at the heart of this book (p. 137). Phillips tackles the difficult issues of objectification and commodification straightforwardly and carefully. While she says that in slavery, sex-trafficking and wife selling, 'the person becomes literally an object', she adds that this remains a matter of degree, 'for people are mostly too recalcitrant to be consistently treated as things', but goes on to warn against accommodating too much by simply refusing the label of objectification (p. 23). This approach involves not taking the narratives of altruism offered by some surrogate mothers at face value, but instead exploring surrogacy as a form of work, an extreme instance of what we risk in any kind of labour by transferring elements of our authority over our bodies to those who employ us (p. 82). The surrogacy contract is about putting yourself in someone else's power, and being managed, manipulated and regulated in mind as well as body. Women's narratives of surrogacy that stress the altruism of the exchange and the gift, Phillips argues, reveal the difficulty of the work, and the ambiguities and tensions generated where the regulation of women's bodies and emotions reach 'troubling levels' (p. 91). She tells her readers that the surrogacy chapter gave her the most difficulty because her own views changed in the course of the research 'and because the position I ultimately settle on may seem patronising or ignorant to those who have chosen surrogacy' (p. 71).

There is something disarming about this, and Phillips' authorial voice throughout the book is reassuring and friendly. It is refreshing to find political theory written as a dialogue with the audience in this way, anticipating interesting objections, recognising the substance of the arguments and the big, behind-the-scenes questions rather than constantly debating the small stuff. Phillips is good at tackling the 'so what?' question and at finding her way through terrain that others find deeply troubling and disorientating, such as the debates around prostitution and about the value of claiming a property in the person. She is fully aware of the limitations of the abstractions of political theory, reminding us that in the translations from theoretical to practical discourse, concepts tend to resume the shape they had before their 
theoretical refinement, and we cannot just make them mean what we want them to mean' (p. 131). All this is salutary and engaging, and the book makes an interesting and challenging companion to Margaret Radin's Contested Commodities, Michael Sandel's What Money Can't Buy, and in a different way, to Cécile Fabre's Whose Body is it Anyway?

And yet I keep returning to Phillips' own doubts about the surrogacy chapter. I do not find her position patronising or ignorant, but I do think it needs to say more about the risks of 'discursive colonialism' and to look in more detail at the ethnographies of surrogacy workers' accounts of their labour, and the ways in which it is stigmatised in some of the same ways as prostitution in India. For a book that is about labour and inequality, it seems odd not to engage with surrogacy as 'sexualised care work', or to explore in more detail how paid reproductive work is raced as well as gendered, both in India and in the United States as well as between the global North and the global South. The book ignores the broader politics of care, and so sidesteps a whole set of questions about 'doing the dirty work', about the difference between payment and compensation and about group-based inequalities that are highly relevant to her argument. Phillips makes a plausible case for not writing this book about prostitution, but it is haunted by the issues and questions commercial sex work raises about inequality, embodiment and labour. The narratives from surrogacy workers in developing countries are not about altruism, but about discipline, regulation and surveillance, and about living and surviving in an economy of maternity which forces women to take on and carry the burdens of their bodies in different but always interdependent ways. Although I agree with Phillips that commodifying women's reproductive labour reinforces stereotypes about women as 'baby-machines', the vulnerabilities of women's bodies vary across different labour markets and the experience of embodiment, of not just having but being bodies (p. 111), is not always an experience of equality, or of sharing the same world.

Laura Brace

University of Leicester, Leicester LE1 7RH, UK 